\title{
Síndrome con defectos radiales, labio leporino complicado y ectrodactilia
}

\author{
Dr. José Ignacio Infante L. ${ }^{1}$; Dra. Lilian Jara $S^{2}{ }^{2}$ Dr. Alejandro Ondarza G. ${ }^{2}$ \\ Srta, Velvet Ghog G. ${ }^{3}$; Sr. Johnny Yáñez P. ${ }^{3}$
}

\section{Familial complicated cleft palate radial defects and ectrodactily}

\begin{abstract}
A syndrome complex claracterized by radial defects, ectrodactily, cleft lip and cleft palate, appeating along three generations is described. An autosomal dominant type of inheritance of low penetrance and variable expression is proposed. The involved gen was one probably active at the first steps of the embryonary period.

(Key words: cleft palate, ectrodactily and radial defects, genes, dominant.)
\end{abstract}

Las alteraciones congénitas de las manos se han clasificado desde diversos puntos de vista: anatómico, embriológico, funcional y radiológico $^{1-5}$. Hemos utilizado la clasificación de Temtamy' que pone énfasis en los factores genéticos como causa de estas afecciones y que define defecto radial como la hipoplasia del pulgar, el primer metacarpiano o ambos con varios grados de severidad clinica ${ }^{6}$; ectrodactilia como la ausencia de uno o más dedos centrales ${ }^{1,7}$. Se han descrito numerosas anomalías asociadas a cada uno de estos tipos de malformaciones de las manos ${ }^{\mathbf{s}}$; sin embargo, no hemos encontrado publicada la asociación de defectos radiales, ectrodactilia y labio leporino en casos aislados o formando parte de una familia, lo que ocurre en la familia que describe esta comunicación.

\section{MATERLAL Y METODO}

Se estudiaron tres generaciones de una familia formada por quince miembros, de los cuales diez eran consanguíneos, afectados por malformaciones de las manos y labio leporino complicado, mediante una ficha diseñada para la búsqueda de malformaciones de origen genético, incluyendo cxamen físico completo, radiografías de ambas manos y antebrazos y genealogía de la familia.

1. Departamento de Pediatría y Cirugía Infantil Sur. Facultad de Medicina, Universidad de Chile.

2. Departamento de Ciencias Médico-Biológicas y Bá. sicas Sur. Facultad de Medicina, Universidad de Chile.

3. Ayudantes alumnos División Ciencias Médicas Sur. Facultad de Medicina, Universidad de Chile.

\section{RESULTADOS}

De diez pacientes consanguineos fue posible examinar a nueve, pues uno había fallecido. Su genealogía se muestra en la figura 1.

Las malformaciones encontradas fueton: aplasia bilateral del pulgar, pulgar flotante bilateral, pulgar flotante unilateral, aplasia del índice unilateral y labio leporino complicado (figura 2).

La asociación de estas alteraciones y su frecuencia se muestran en la tabla 1, observándose en los ocho casos alteraciones del pulgar, en dos casos asociado a labio leporino y en un caso a ectrodactilia del índice en la mano contralateral como se muestra en la figura $2 \mathrm{C}$.

\section{Tabla 1}

Malformaciones $y$ sus frecuenclas (Número de pacientes consanguíneos afectados. $N=8$ )

Malformación sólo del pulgar 5

- Aplasia bilateral

- Pulgar flotante bilateral 1

Malformación del pulgar con

labio leporino complicado

- Aplasia bilateral con labio leporino complicado

- Pulgar flotante bilateral con labio leporino complicado

Malformación del pulgar con malformación del índice 
II

(1)
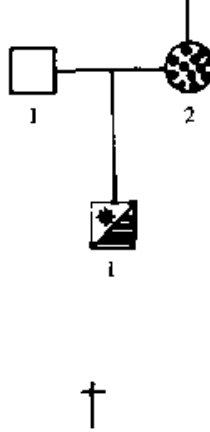

Fallecuds
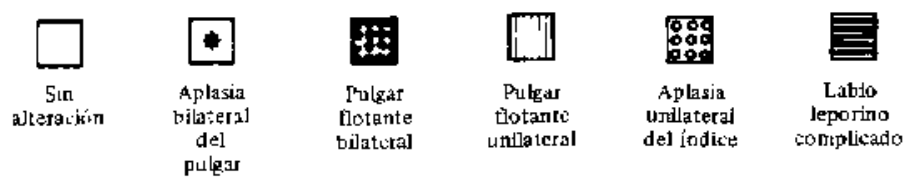

Figura 1: Gencalogía que muestra los 9 pacientes afectados en 3 generaciones.
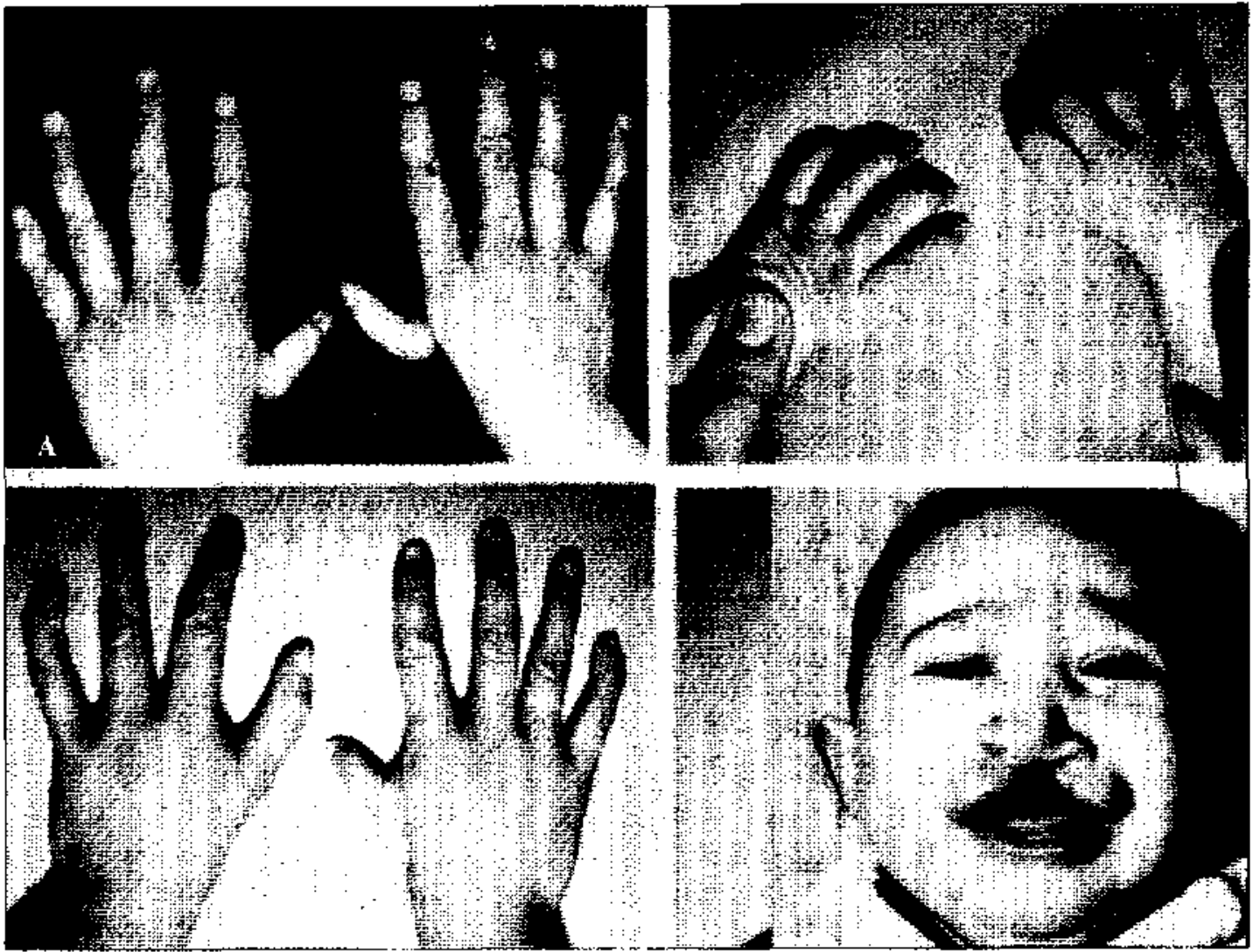

Figura 2: A. Pulgarcs flotantes bilaterales. B. Ausencia de ambos pulgares. C. Ausencia de índice a izquierda y pulgar flutante a derecha. D. Labio y paladar hendido. 
Las alteraciones radiológicas fueron: pulgar con tres falanges y sólo epífísis distal del primer metacarpiano, pulgar con dos falanges con eṕf $j$ sis distal del primer metacarpiano, pulgar con fusión de falanges, ausencia de pulgar y primer metacarpiano, ausencia de índice y segundo metacarpiano, con fusión parcial de huesos del carpo (figura 3 ).

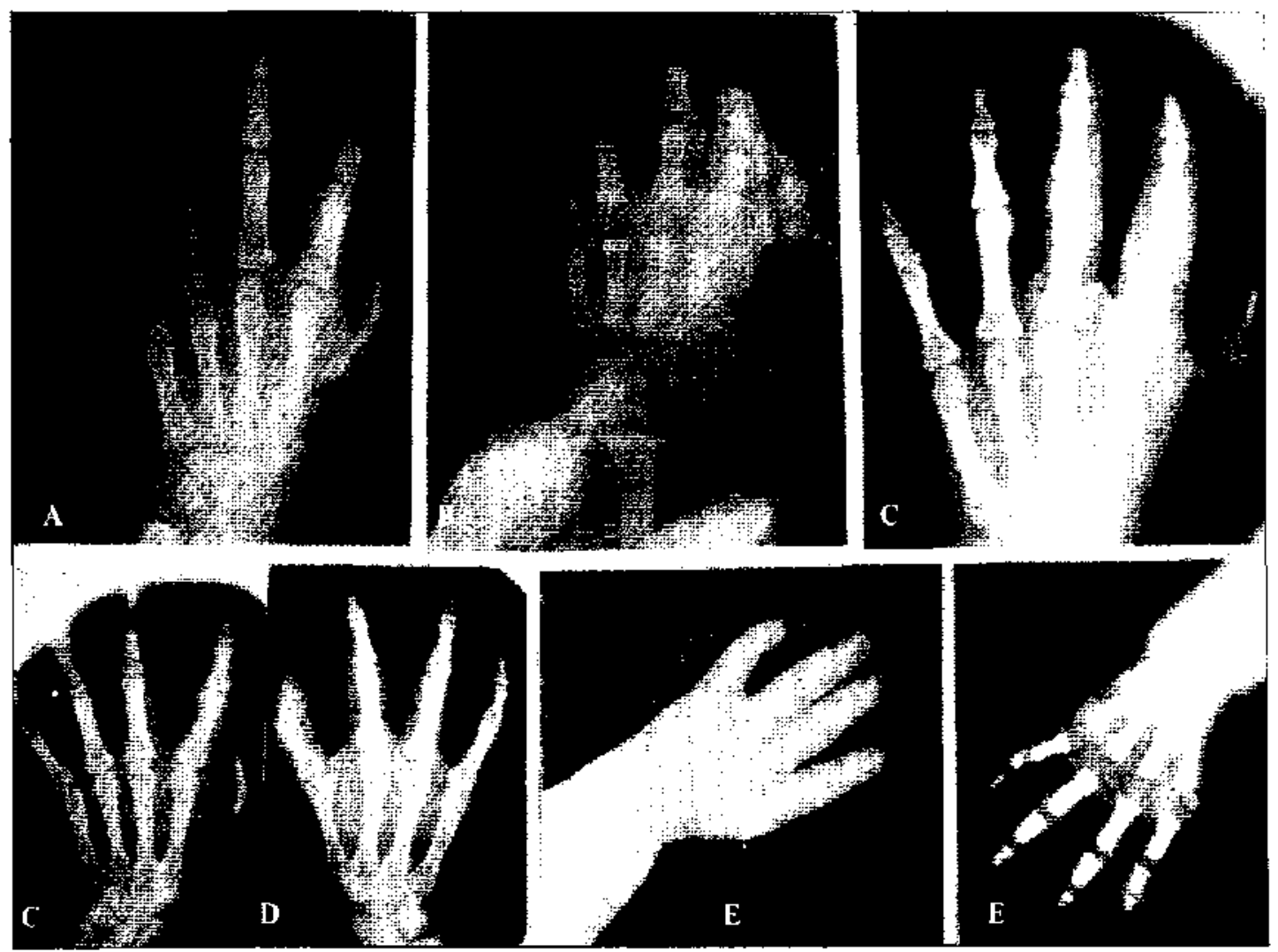

Figura 3: A. Pulgar con dos falanges y cabeza de 1er. metacarpiano. B. Putgar con tres falanges y cabeza de 1er. metacarpiano, C. Pulgar con fusión de falanges. D. Ausencia de indice y $2^{\circ}$ metacarpiano. E. Ausencia de pulgares.

\section{COMENTARIO}

Las estructuras alteradas en nuestros pacientes son de origen ectomesodérmico y se desarrollan en forma paralela durante el período embrionario desde la quinta semana de gestación, por lo que creemos que la alteración génica se encuentra a nivel de genes que regulan el desarrollo temprano de estas estructuras y que tendrían un efecto sjmultáneo en la embriolngía de la cara y las extremidades.

Por la frecuencia de aparición de los caracteres somáticos anormales se plantea que el gen alterado se hereda en esta familia como autosómico dominante con penetrancia incompleta y exprcsividad variable.

\section{RESUMEN}

Se presenta una familia formada por quince miembros, de los cuales diez son consanguíneos portadores de una asociación de defecto radial, labio leporino complicado y ectrodactilia, lo que se hereda en forma autosómica dominante con penetrancia incompleta y expresividad variable. Se postula una alteración génica a nivel de genes que actúan durante el período embrionario.

\section{REFERENCIAS}

1. Temtamy S.A. and AC Kusick V.A.: Synosis of hand malformations with particular emphasis on genetic factors. In Bergma D. (ed): Part III Limb 
Malformations. Bïrth Defects: Orig Art Ser, Vol. 5, No 3, New York: The National Foundation, March of Dimes, 1969, p. 125.

2. Swonson A.B., Bonky A.J, Entin M.A.: Classification of limb malformations on the basis of embryological failures. Surg Clin North Am 1968; 48: 1169-1178.

3. Flatt A.E.: A test of classification of congenital anomalies of the upper extremity. Surg Clin North Am 1970; 50 : 509-516.

4. Kay A.E., Day H.J.B., Henkel H.L. et al.: A pro. posed international terminology for the classifica- tion of congenital limb defjciences.Orthot Prosthet $1974 ; 28: 33-48$.

5. Swanson A.B.: A classification for congenjtal limb malformation. J Hand Surg 1976; 1: 8-22.

6. Temtamy S.A.: On anomalies associated with radial dy splasia. J Pediatr 1974; 85: 585.

7. David T.S.: The differential diagnosis of the cleft hand and cleft foot malformation. Hand 1974; 6: 58 .

8. Carroll R.E. and Louis D.S.: Anomalies associated with radial dysplasia. J Pediatr 1974;84: 409. 